\title{
Azo polymers with electronical push and pull structures prepared via RAFT polymerization and its photoinduced birefringence behavior
}

\author{
H. Z. Cao ${ }^{1}$, W. Zhang ${ }^{1}$, J. Zhu1, X. R. Chen ${ }^{2}$, Z. P. Cheng1, J. H. Wu ${ }^{2}$, X. L. Zhu ${ }^{1 *}$ \\ ${ }^{1}$ Key Laboratory of Organic Synthesis of Jiangsu Province, School of Chemistry and Chemical Engineering, \\ Soochow (Suzhou) University, 215006 Suzhou, China \\ ${ }^{2}$ Institute of Information Optical Engineering, Soochow (Suzhou) University, 215006 Suzhou, China
}

Received 12 May 2008; accepted in revised form 9 July 2008

\begin{abstract}
Two methacrylate monomers containing azo and electronical push and pull structure, e.g. 2-Methyl-acrylic-acid2-\{[4-(4-cyano-phenylazo)-3-methyl-phenyl]-ethyl-amino-ethyl ester (MACP) with cyano substituted and 2-Methylacrylic-acid-2-\{ethyl-[4-(4-methoxy-phenylazo)-3-methyl-phenyl]-amino\}-ethyl ester (MAMP) with methoxy substituted, were synthesized and polymerized using 2-cyanoprop-2-yl dithiobenzoate (CPDB) as chain transfer agent and 2,2'-azobisisobutyronitrile (AIBN) as initiator. The results showed that the polymerization displayed characteristics of 'living'/controlled free radical polymerization. Thus, the obtained polymers, polyMACP (pMACP) and polyMAMP (pMAMP), had controlled molecular weights and narrow molecular weights distribution. The chain extension experiments of pMACP and pMAMP using styrene as the second monomer were successfully carried out. The photo-induced trans-cis-trans isomerization kinetic of pMACP and pMAMP in chloroform solution were described. Marked differences in rate for the trans-cis and cis-trans isomerization of pMACP and pMAMP were observed in chloroform solution due to the different electronic effects in these two polymers. Photoinduced birefringence and surface relief grating (SRG) of the pMACP and pMAMP were investigated in thin film state.
\end{abstract}

Keywords: polymer synthesis, azopolymers, photo-induced birefringence, surface relief grating (SRG), reversible additionfragmentation chain transfer polymerization (RAFT)

\section{Introduction}

Azobenzene-containing polymers received more and more attentions in this decade for their potential applications in many fields, such as optical data storage [1, 2], nonlinear optical materials [3, 4], holographic memories [5, 6], chiroptical switches $[7,8]$ and surface relief gratings (SRG) $[9,10]$. The photo-responsive properties of the azopolymers are based on the trans-to-cis and cis-to-trans photo isomerizations of azo chromophores, which leads to considerable changes in their molecular shape and dipole moments $[11,12]$. It is generally accepted that in the surface relief gratings (SRG) forming process, the large-scale mass transport of the azopolymer chains is caused by the photoinduced trans-cis-trans isomerization cycles of azo chromophores, which results in the surface modulation in a reversible way. A considerable amount of literature has been devoted to the dynamic processes of the SRGs formation and several models have been proposed to describe the mechanism of the large photoinduced mass transport [13-16].

On the other hand, the optically induced birefringence can be produced on azobenzene-containing

*Corresponding author, e-mail: xlzhu@suda.edu.cn

(C) BME-PT and GTE 
polymers by linearly polarized (LP) photoexcitation of the azobenzene group, which undergoes trans-cis-trans isomerization $[17,18]$, giving rise, after repeated photoexcitation and isomerization cycles, to a net excess of azobenzene moieties oriented with their transition dipole moments perpendicularly to the direction of the pump electric field. The anisotropic distribution of chromophores provides birefringence and linear dichroism of the film can be erased by irradiation with depolarized or circularly polarized (CP) light, thus reproducing the original isotropy in the material. According to Rabek's report [19], azo compounds can be divided into three classes: azobenzene type, aminoazobenzene type and pseudo-stilbene type. Azobenzene containing compounds with electronical push and pull structures (pseudo-stilbene type) and aminoazobenzene type molecules can isomerize from $\mathrm{cis}$ configuration back to trans configuration very quickly at room temperature. However, the thermal cis-trans isomerization in azobenzene-type molecules is relatively slow, and it is even possible to isolate the cis isomer [20].

Typically, the azobenzene containing polymers can be obtained through two ways: incorporating azobenzene chromophores into the backbones directly during the polymerization process [21-23], and postpolymerization modification technique [24-27]. Generally, conventional free radical polymerization (uncontrolled radical polymerization) can be used for the facile synthesis of polymers with side-chain containing azobenzene chromophores with high functionality. However, the structures of polymers obtained by this way can not be tailored and are usually ill-defined. Anionic polymerization has been used to synthesize welldefined end-functional polymers with predetermined molecular weights and narrow molecular weight distributions. However, the reaction conditions are very stringent and the range of polymerisable monomers is quite limited. The 'living'/ controlled free radical polymerization (LFRP) [28-39], developed rapidly during the past decade, was a frequently used technology in the preparation of well-defined polymers. Among the LFRP techniques, the reversible addition-fragmentation chain transfer (RAFT) polymerization is considered as one of the most versatile method with wide range of polymerisable monomer and undemanding polymerization conditions.

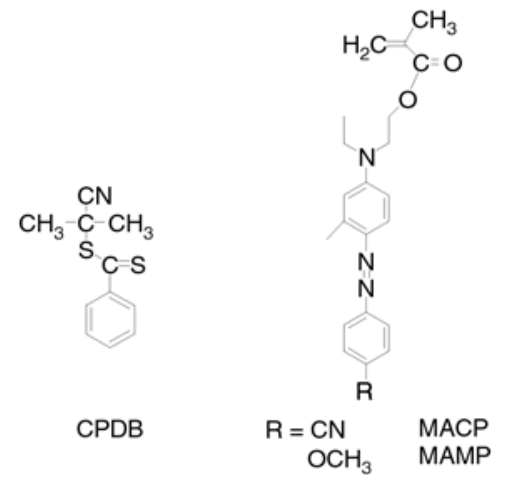

Figure 1. Chemical structures of 2-cyanoprop-2-yl dithiobenzoate (CPDB), 2-methyl-acrylic-acid-2-\{[4(4-cyano-phenylazo)-3-methyl-phenyl]-ethylamino -ethyl ester (MACP) and 2-methylacrylic-acid-2-\{ethyl-[4-(4-methoxy-phenylazo)3-methyl-phenyl]-amino -ethyl ester (MAMP)

Herein, we report a detailed study of RAFT polymerization of two methacrylate monomers, bearing azobenzene moieties with different push and pull substituted groups at 4-position in the benzene rings, e.g. MACP with cyano group substituted while MAMP with methoxy substituted (as showed in Figure 1). To study the effect of the polarity of substitutional groups, cyano and methoxy on the photo-responsive behaviors, the photo-induced trans-cis-trans isomerization kinetic of the polymers from RAFT polymerization were described. Furthermore, photoinduced birefringence and SRGs of these polymers were investigated in thin film state.

\section{Experimental section}

\subsection{Materials}

Methacryloyl chloride was purchased from Haimen Best Fine Chemical Industry Co. Ltd. (Jiangsu, China) and used after distillation. Styrene (St, 99\%, Shanghai Chemical Reagent Co. Ltd. China) was washed with a 5\% sodium hydroxide aqueous solution and then with deionized water until neutralization. After being dried with anhydrous magnesium sulfate overnight, it was distillated over $\mathrm{CaH}_{2}$ under vacuum and stored at $-18^{\circ} \mathrm{C} .2,2^{\prime}$-azobisisobutyronitrile (AIBN, 97\%, Shanghai Chemical Reagent Co. Ltd. China) was recrystallized from ethanol twice, dried under vacuum at room temperature, and stored at $-18^{\circ} \mathrm{C}$. Anisole and chloroform (analytical grade) were purchased from Shanghai Chemical Reagent Co. Ltd (China) and used after 


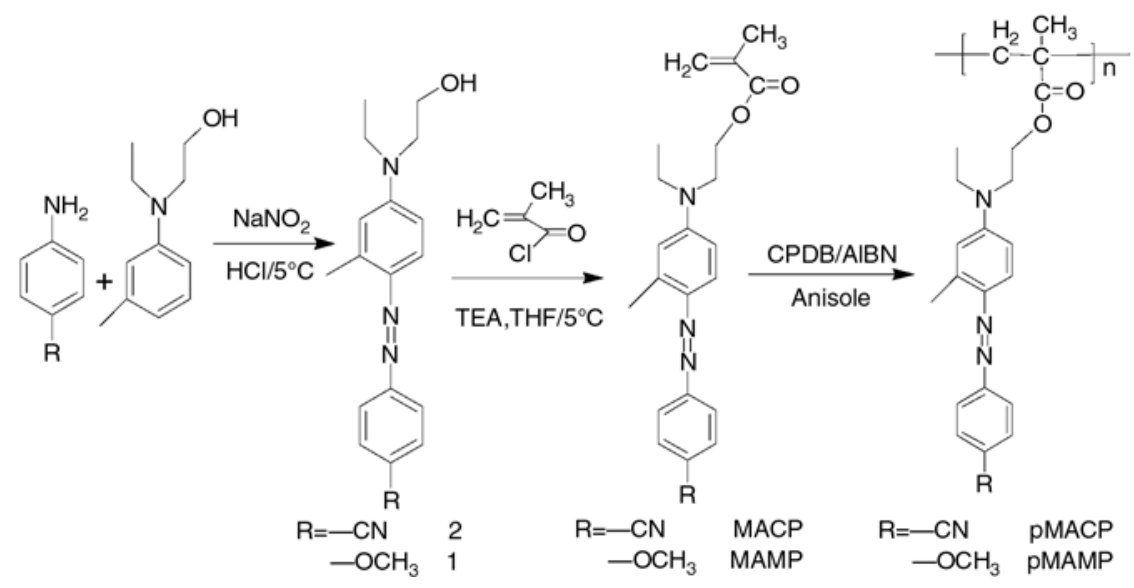

Figure 2. The synthetic routes of MACP, MAMP, pMACP and pMAMP

distillation. N-Ethyl-N-2-hydroxyethylm-toluidine (TCI, Tokyo Kasei Kogyo Co. Ltd. Japan, 99\%) and 4-aminobenzonitrile (Alfa, A Johnson company, USA, 98\%) were used as received. 2Cyanoprop-2-yl dithiobenzoate (CPDB, as in Figure 2) was synthesized according to the literature [40]. The synthetic routes of MACP and MAMP are presented in Figure 2. Other materials were purchased from Shanghai Chemical Reagent Co. Ltd. China and purified according to the standard method.

\subsection{Synthesis of MAMP and MACP}

\section{2-\{Ethyl-[4-(4-methoxy-phenylazo)-3-methyl- phenyl]-amino\}-ethanol (1)}

4-Methoxyanhiline $(4.96 \mathrm{~g}, 40 \mathrm{mmol})$ was dissolved in an aqueous solution of sodium nitrite ( $3.38 \mathrm{~g}$ in $40 \mathrm{ml}$ of deionized water). The obtained solution was cooled to $0-5^{\circ} \mathrm{C}$ and then hydrochloric acid $(16 \mathrm{ml})$ in $100 \mathrm{ml}$ deionized water was added slowly with stirring. After stirring for further $30 \mathrm{~min}$, carbamide $(0.48 \mathrm{~g}, 8 \mathrm{mmol})$ was added to demolish the residual sodium nitrite with tracking by starch-iodide paper. Then the diazonium salt solution was obtained. A solution of N-ethyl-N-2hydroxyethylm-toluidine $(8.78 \mathrm{~g}, 48 \mathrm{mmol})$, glacial acetic $(15 \mathrm{ml})$ and deionized water $(30 \mathrm{ml})$ prepared beforehand was slowly added to the diazonium salt solution at $0-5^{\circ} \mathrm{C}$. The mixture was vigorously stirred for $30 \mathrm{~min}$ in ice bath and aqueous sodium hydroxide solution was added to adjust the $\mathrm{pH}$ to $5-7$. The solution was heated to $40-50^{\circ} \mathrm{C}$ gradually and kept for $15 \mathrm{~min}$, and then it was cooled for $2 \mathrm{~h}$. The solid was filtered and dried under vacuum at room temperature. After recrystallized from ethanol-water mixture $(3: 2, \mathrm{v}: \mathrm{v})$, the compound 1 was obtained as a yellow crystalline solid (7.5 g, 68\%). ${ }^{1} \mathrm{H}$ NMR $\left(\mathrm{CDCl}_{3}\right)$ : 7.80-7.88(d, $2 \mathrm{H}), 7.66-7.73(\mathrm{~d}, 1 \mathrm{H}), 6.89-7.03(\mathrm{~d}, 2 \mathrm{H}), 6.62(\mathrm{~s}$, $2 \mathrm{H}), 3.80-3.90(\mathrm{t}, 5 \mathrm{H}), 3.46-3.60(\mathrm{~m}, 4 \mathrm{H}), 2.69(\mathrm{~m}$, $3 \mathrm{H}), 1.58(\mathrm{~s}, 1 \mathrm{H}), 1.14-1.28(\mathrm{t}, 3 \mathrm{H})$. Anal. Calcd. for $\mathrm{C}_{18} \mathrm{H}_{23} \mathrm{~N}_{3} \mathrm{O}_{2}$ : C 68.98, H 7.40, N 13.41; found: C 68.65, H 7.41, N 12.95 .

\section{2-Methyl-acrylic-acid-2-\{ethyl-[4-(4-methoxy- phenylazo)-3-methyl-phenyl]-amino\}-ethyl ester (MAMP)}

Compound 1 (6.2 g, $20 \mathrm{mmol})$, dry THF $(50 \mathrm{ml})$ and triethylamine $(2.8 \mathrm{ml})$ was added to a roundbottom flask, then the mixture was cooled with ice bath. Methacryloyl chloride $(1.9 \mathrm{ml}, 22 \mathrm{mmol})$ diluted in dry THF $(10 \mathrm{ml})$ was added dropwise to the cooled compound 1 solution. The resultant mixture was vigorously stirred for $1 \mathrm{~h}$ at $0-5^{\circ} \mathrm{C}$ and then at room temperature for further $6 \mathrm{~h}$. The solution was filtered and the solvent was removed by rotary evaporation. The crude product was dissolved in dichloromethane and washed with deionized water three times, then dried with anhydrous magnesium sulfate overnight. Finally, the obtained crude product was purified by column chromatography (silica gel $\mathrm{H}$ ) with petroleum ether/ethyl acetate $=4: 1(\mathrm{v}: \mathrm{v})$ as eluent to give a yellow crystalline solid MAMP (4.3 g, 56.4\%). ${ }^{1} \mathrm{H}$ NMR $\left(\mathrm{CDCl}_{3}\right): 7.81-7.93(\mathrm{~d}, 2 \mathrm{H}), 7.72-7.75(\mathrm{~s}, 1 \mathrm{H})$, 6.97-7.01(d, 2H), 6.62(s, 2H), 6.13(s, 1H), 5.6(s, $1 \mathrm{H}), 4.32-4.39(\mathrm{t}, 2 \mathrm{H}), 3.89(\mathrm{~s}, 3 \mathrm{H}), 3.66-3.72(\mathrm{t}$, $2 \mathrm{H}), 3.45-3.57(\mathrm{~m}, 2 \mathrm{H}), 2.7(\mathrm{~s}, 3 \mathrm{H}), 1.96(\mathrm{~s}, 3 \mathrm{H})$, 
1.22-1.27(t, 3H). Anal. Calcd. for $\mathrm{C}_{22} \mathrm{H}_{27} \mathrm{~N}_{3} \mathrm{O}_{3}$ : C 68.9, H 7.15, N 10.73; found: C 69.27, H 7.13, N 11.02 .

\section{4-\{4-[Ethyl-(2-hydroxy-ethyl)-amino]-2-methyl- phenylazo\}-benzonitrile (2)}

The compound 2 was synthesized using a similar procedure as compound 1 as a red crystalline solid (9.29 g, 75.4\%). ${ }^{1} \mathrm{H} \mathrm{NMR}\left(\mathrm{CDCl}_{3}\right) 7.84-7.94(\mathrm{~d}$, 2H), 7.75-7.84(s, 1H), 7.65-7.78(d, 2H), 6.62(s, $2 \mathrm{H}), 3.88(\mathrm{~s}, 2 \mathrm{H}), 3.47-3.65(\mathrm{~m}, 4 \mathrm{H}), 2.68(\mathrm{~s}, 3 \mathrm{H})$, $1.56(\mathrm{~s}, 1 \mathrm{H}), 1.18-1.30(\mathrm{t}, 3 \mathrm{H})$. Anal. Calcd. for $\mathrm{C}_{18} \mathrm{H}_{20} \mathrm{~N}_{40}$ : C 69.93, H 6.69, N 18.61; found: C 70.11, H 6.54, N 18.17 .

\section{2-Methyl-acrylic-acid-2-\{[4-(4-cyano- phenylazo)-3-methyl-phenyl]-ethyl-amino\}- ethyl ester (MACP)}

MACP was synthesized using a similar procedure as MAMP. It was purified by column chromatography (silica gel $\mathrm{H}$ ) with petroleum ether/ethyl acetate $=10: 1(\mathrm{v}: \mathrm{v})$ as eluent, producing a red crystalline solid MACP $(4.8 \mathrm{~g}, 63 \%) .{ }^{1} \mathrm{H}$ NMR $\left(\mathrm{CDCl}_{3}\right)$ : 7.86-7.91(d, 2H), 7.78-7.82(d, $\left.1 \mathrm{H}\right)$, 7.71-7.76(d, 2H), 6.62-6.64(t, 2H), 6.11(s, 1H), 5.59(s, 1H), 4.33-4.39(t, 2H), 3.66-3.78(t, 2H), 3.44-3.59(m, 2H), 2.69(s, 3H), 1.92-1.98(d, 3H), 1.22-1.29(t, 3H). Anal. Calcd. for $\mathrm{C}_{22} \mathrm{H}_{24} \mathrm{~N}_{4} \mathrm{O}_{2}$ : C 69.90, H 6.54, N 14.77; found: C 70.19, H 6.43, N 14.88 .

\subsection{RAFT Polymerization of MACP and MAMP}

The following procedure was typical as in Figure 2: a master batch of AIBN $(4.1 \mathrm{mg}, 0.025 \mathrm{mmol})$ and CPDB (33.2 mg, $0.15 \mathrm{mmol}$ ) was dissolved in anisole $(10 \mathrm{ml})$ and aliquot of $1 \mathrm{ml}$ was placed in a $5 \mathrm{ml}$ ampoule with MAMP (381.5 mg, $1.00 \mathrm{mmol}$ ) added in advance. The contents were purged with argon for approximately 20 min to eliminate the oxygen. Then, the ampoules were flame-sealed and placed in an oil bath held by a thermostat at $80^{\circ} \mathrm{C}$ to polymerize. After predetermined time, each ampoule was quenched in ice water and opened. The reaction mixture was diluted with $2 \mathrm{ml}$ of THF and precipitated into $200 \mathrm{ml}$ of methanol. The polymers were dried under vacuum at room temperature to constant weight. The conversion was determined by gravimetry. The RAFT polymerization of MACP was used a similar procedure as that of MAMP. The polymers from MACP and MAMP are referred as pMACP and pMAMP, respectively.

\subsection{Chain extension of pMACP and pMAMP with styrene (St) as the second monomer}

The RAFT polymerization of St was carried out with the similar procedure as mentioned above, except that CPDB was replaced by pMACP and pMAMP obtained from the polymerization of MACP and MAMP.

\subsection{Preparation of the polymer film}

pMACP or pMAMP was dissolved in chloroform with concentration of $0.1 \mathrm{~g} \cdot \mathrm{ml}^{-1}$. The obtained azopolymer solutions were filtered by mesh filter with $0.2 \mu \mathrm{m}$ of pore size. Thin films were prepared on glass substrates by spin coating at $2500 \mathrm{rpm}$. The thickness of the film was controlled to be in the interval of 100-200 nm. After dried in vacuum oven for $24 \mathrm{~h}$, the amorphous film with good optical quality was obtained and stored in desiccator for further study.

\subsection{Instruments for characterization}

${ }^{1} \mathrm{H}$ NMR spectra were obtained on an Inova $400 \mathrm{MHz}$ spectrometer using $\mathrm{CDCl}_{3}$ as a solvent. Gel permeation chromatography (GPC) analysis was carried out on waters 1515 chromatography equipped with a refractive index detector with THF as an eluent and poly(methyl methacrylate) (PMMA) as standard sample. The UV-vis absorption spectra of the polymers in chloroform solutions were determined on a Shimadzu-RF540 spectrophotometer. Film thickness was measured on Ambios-step XP-2 profiler. The birefringence was

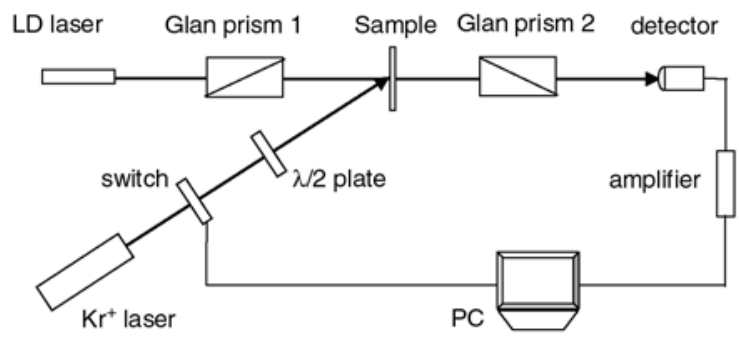

Figure 3. Setup for producing and detecting the birefringence effect of the sample 
measured with a pump $\mathrm{Kr}^{+}$laser beam $(413.1 \mathrm{~nm}$, $5 \mathrm{~mW} / \mathrm{cm}^{2}$ ) polarized at $45^{\circ}$ with respect to the probe beam polarization. The experimental setup is shown in Figure 3. The sample was placed between two crossed polarizers. The transmitted probe beam (650 $\mathrm{nm}$ diode laser) was detected by a photoelectric cell and connected to a computer through an amplifier. The photoinduced birefringence values of the films were obtained from transmitted intensity measurements. The other experimental setup for surface relief gratings (SRGs) fabrication was similar to that reported in the literature [41]. A linearly polarized $\mathrm{Kr}^{+}$laser beam $(413.1 \mathrm{~nm}$, $30 \mathrm{~mW} / \mathrm{cm}^{2}$ ) was used as the light source. SRGs were optically inscribed on the polymer films with p-polarized interfering laser beams. The surface morphology of the gratings was determined by atomic force microscopy (AFM) (NT-MDT SOLVER P47-PRO). The diffraction efficiency of the gratings was monitored by measuring the firstorder diffracted beam intensity of an unpolarized low power diode laser beam $(650 \mathrm{~nm})$ in transmission mode.

\section{Results and discussion}

\subsection{RAFT polymerizations of MAMP and MACP}

RAFT polymerization technique was considered as the one of the most versatile methods to synthesize polymers with well-defined structure under the moderate conditions. The RAFT polymerization of

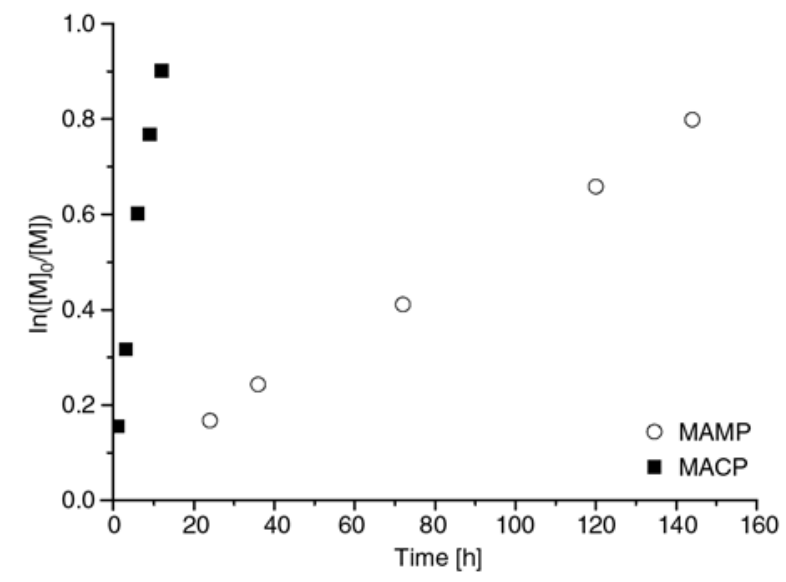

Figure 4. Relationships between $\ln \left([\mathrm{M}]_{0} /[\mathrm{M}]\right)$ and the polymerization time for the RAFT polymerization of $\mathrm{MACP}$ at $70^{\circ} \mathrm{C}$ and MAMP at $80^{\circ} \mathrm{C}$ in anisole solution. $[\mathrm{MACP}]_{0}:[\mathrm{AIBN}]_{0}:[\mathrm{CPDB}]_{0}=$ $200: 1: 3$; $[\mathrm{MAMP}]_{0}:[\mathrm{AIBN}]_{0}:[\mathrm{CPDB}]_{0}=$ 200:0.5:3 azo monomer has been demonstrated in the literatures $[37,38]$. The MACP and MAMP with electronic push and pull structures were designed in order to improve the thermal cis-trans isomerization rate $[19,20]$. The RAFT polymerizations of $\mathrm{MACP}$ at $70^{\circ} \mathrm{C}$ and MAMP at $80^{\circ} \mathrm{C}$ in anisole solution were carried out with $\mathrm{CPDB}$ as a RAFT agent and AIBN as an initiator ([MACP $]_{0}:[\mathrm{AIBN}]_{0}$ : $[\mathrm{CPDB}]_{0}=200: 1: 3,[\mathrm{MAMP}]_{0}:[\mathrm{AIBN}]_{0}:[\mathrm{CPDB}]_{0}=$ 200:0.5:3). It was found that at $70^{\circ} \mathrm{C}$, the RAFT polymerization of MAMP was very slow. After 336 hours of polymerization, only $20.1 \%$ of conversion was obtained ([MAMP $]_{0}:[\mathrm{AIBN}]_{0}$ : $\left.[\mathrm{CPDB}]_{0}=200: 1: 3\right)$. The RAFT temperature of MAMP was thus set at $80^{\circ} \mathrm{C}$. The polymerization results were summarized in Figure 4 and Figure 5. As shown in Figure 4, the corresponding plot of $\ln \left([\mathrm{M}]_{0} /[\mathrm{M}]\right)$ versus the polymerization time was linear, which indicated that the propagating radical concentrations were almost constant during the processes of the polymerization. The polymerization rate of MACP was much faster than that of MAMP even in a lower reaction temperature, e.g. $70^{\circ} \mathrm{C}$ for MACP and $80^{\circ} \mathrm{C}$ for MAMP.

Figure 5 shows the dependence of $M_{n(G P C) \mathrm{s}}$ and PDIs on the monomer conversions. The $M_{n(G P C) \mathrm{S}}$ increased linearly with increasing monomer conversion, which was consistent with the polymerization proceeding in a controlled fashion. However, the $M_{n(G P C)}$ S were slightly higher than the theoretical values at the early stage of the polymerization, and lower than the theoretical values at relatively

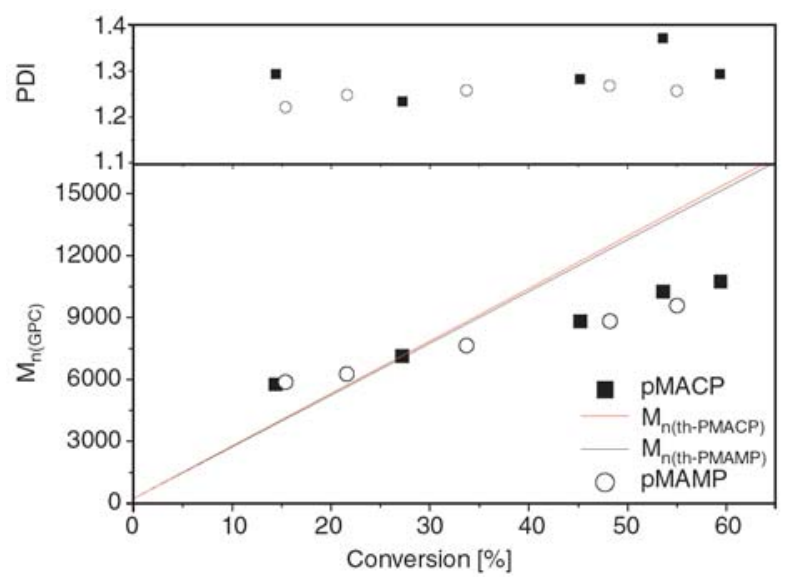

Figure 5. Evolution of $M_{n(G P C)}$ and PDI with monomer conversion for the RAFT polymerization of $\mathrm{MACP}$ at $70^{\circ} \mathrm{C}$ and MAMP at $80^{\circ} \mathrm{C}$ in anisole. Polymerization conditions are the same as in Figure 4. 
high conversions. The theoretical molecular weight $\left(M_{n(t h)}\right)$ was calculated as Equation (1):

$$
\begin{aligned}
M_{n(t h)}= & \frac{[\text { monomer }]_{0}}{[\mathrm{CPDB}]_{0}} \cdot M W_{\text {monomer }} . \\
& \text { conversion }+\mathrm{MW}_{\mathrm{CPBD}}
\end{aligned}
$$

where, $[\text { monomer }]_{0}$ and $[\mathrm{CPDB}]_{0}$ were the initial concentration of monomer and $\mathrm{CPDB}$, respectively, $\mathrm{MW}_{\text {monomer }}$ and $\mathrm{MW}_{\mathrm{CPDB}}$ were the molecular weights of monomers and CPDB, respectively. At the beginning of the polymerization, some positive deviation of $M_{n(G P C)}$ s from the theoretical values $\left(M_{n(t h)} \mathrm{S}\right)$ may be due to the incomplete usage of RAFT agent [42]. And at high monomer conversions, some negative deviation may be due to the side reactions of the initiator or initiator-derived radicals with the RAFT agent [32-36, 40]. On the other hand, the GPC standard calibration samples of PMMA may be the other cause of some deviations for $M_{n(G P C)}$ from the theoretical values. The PDIs of the polymers were relatively low up to high conversions in all cases (PDI $\leq 1.37)$.

\subsection{Synthesis of block copolymer (pMACP-b- PS, pMAMP-b-PS)}

In order to further investigate the living behavior of the polymerization, the obtained polymer pMACP $\left(M_{n}=10560 \mathrm{~g} \cdot \mathrm{mol}^{-1}\right.$, PDI $\left.=1.23\right)$ and pMAMP $\left(M_{n}=6440 \mathrm{~g} \cdot \mathrm{mol}^{-1}\right.$, PDI $\left.=1.26\right)$, were used as the macro-RAFT agents to conduct chain extension experiments using styrene as the second monomer, respectively. The results were summarized in Table 1. The GPC profiles of the original macroRAFT agent and chain extended polymer are shown in Figure 6, which demonstrated obvious peak shift from the macro-RAFT agent to the chain extended polymers. The molecular weight increased from 10560 to $16720 \mathrm{~g} \cdot \mathrm{mol}^{-1}$ for pMACP and 6440 to $10570 \mathrm{~g} \cdot \mathrm{mol}^{-1}$ for pMAMP, respectively, which demonstrated that most of the original polymer chains were active. The GPC traces of chain extended polymers showed trail at the position of

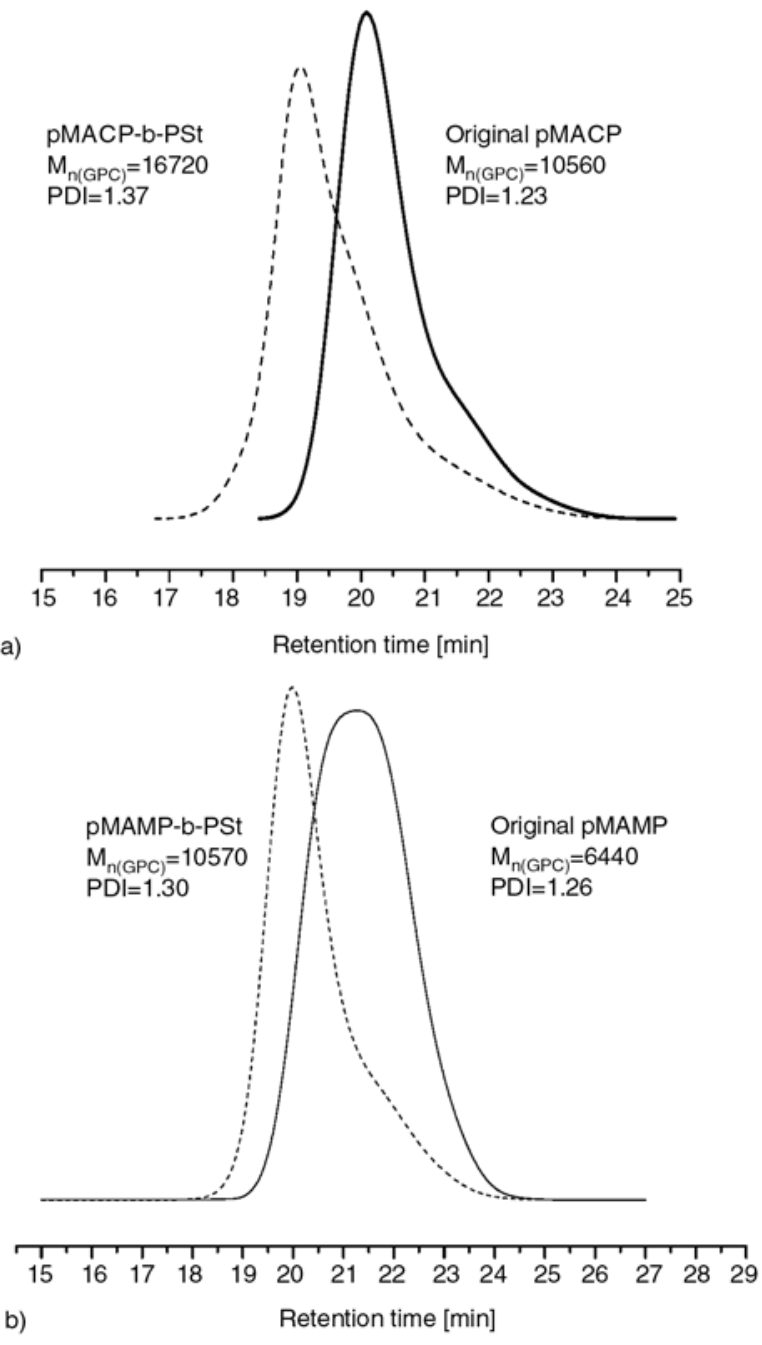

Figure 6. GPC traces for pMACP- $b$-PS (a) and pMAMP$b$-PS (b) for chain extension using pMACP and pMAMP as macro-RAFT agents, respectively

original macro-RAFT agent. This should be caused by the non-dithioester terminated polymer (named as dead polymer) existed in the original macroRAFT agent.

\subsection{Photochemical behaviors}

As mentioned in the introduction part, azobenzene unit showed photo sensitive behaviors. The obtained polymers, pMACP and pMAMP, had high density of azobenzene units in their side chains. Thus, the trans-cis and cis-trans photo isomeriza-

Table 1. Chain-extension results using pMACP and pMAMP as the macro-RAFT agents and styrene as the monomer. $[\mathrm{St}]_{0}:[\mathrm{macro}-\mathrm{RAFT}]_{0}:[\mathrm{AIBN}]_{0}=1000: 3: 1,70^{\circ} \mathrm{C}, 12 \mathrm{~h}$.

\begin{tabular}{|c|c|c|c|c|c|}
\hline \multirow{2}{*}{ Label } & \multicolumn{2}{|c|}{ Macro-RAFT agent } & \multirow{2}{*}{$\begin{array}{c}\text { Conversion } \\
{[\%]}\end{array}$} & \multicolumn{2}{c|}{ After chain extension } \\
\cline { 2 - 3 } \cline { 5 - 5 } & $\mathbf{M}_{\mathbf{n}}$ & PDI & & $\mathbf{M}_{\mathbf{n}}$ & PDI \\
\hline pMACP- $b$-PS & 10560 & 1.23 & 21 & 16720 & 1.37 \\
\hline pMAMP- $b$-PS & 6440 & 1.26 & 14 & 10570 & 1.30 \\
\hline
\end{tabular}



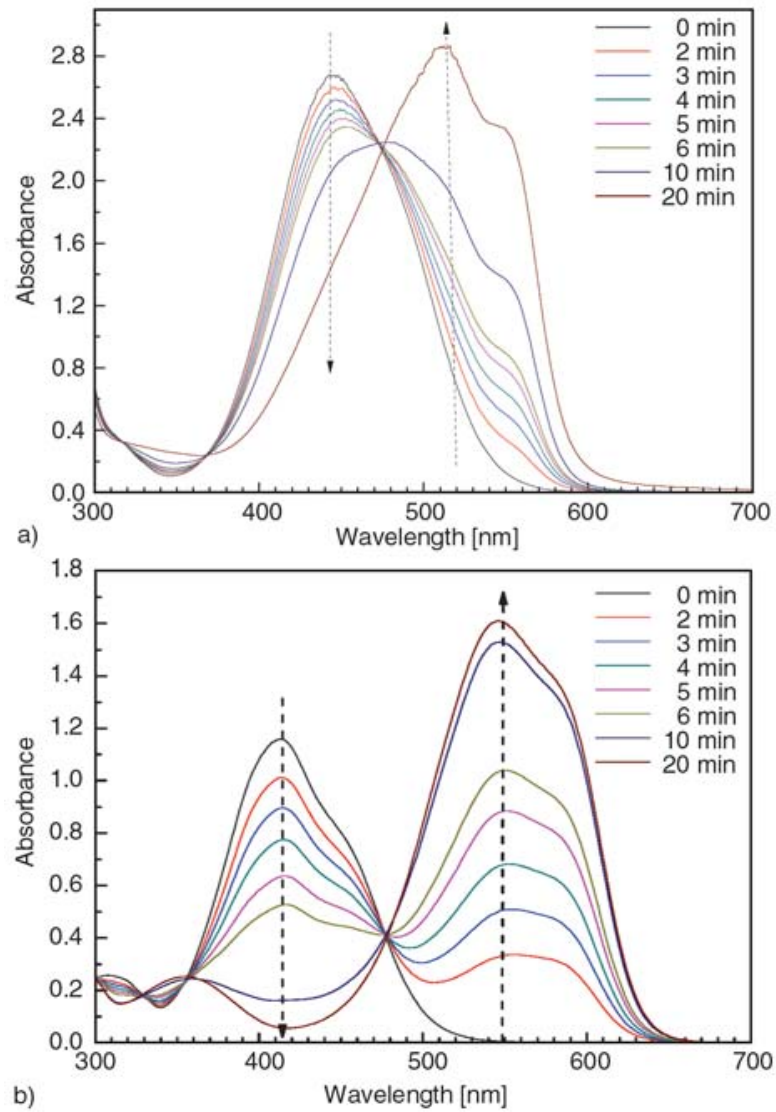

Figure 7. Changes in the UV-vis absorption spectra of pMACP $\left(\mathrm{a}-M_{n(G P C)}=10550 \mathrm{~g} \cdot \mathrm{mol}^{-1}, \mathrm{PDI}=\right.$ $1.30)$ and pMAMP $\left(\mathrm{b}-M_{n(G P C)}=8580 \mathrm{~g} \cdot \mathrm{mol}^{-1}\right.$, $\mathrm{PDI}=1.27$ ) under different irradiation time of $365 \mathrm{~nm}$ of UV light in chloroform solution at room temperature. The concentration of the solution was $2.5 \cdot 10^{-6} \mathrm{~mol} \cdot \mathrm{L}^{-1}$.

a)

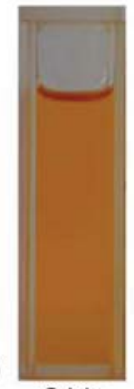

Origin
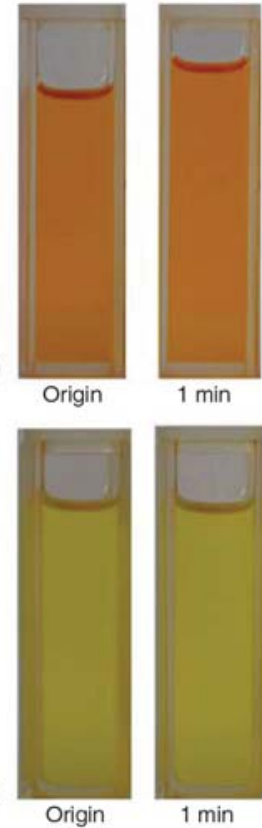

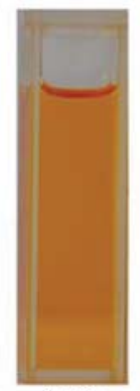

$2 \min$

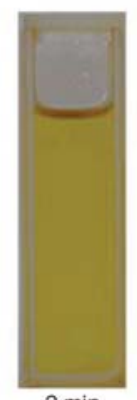

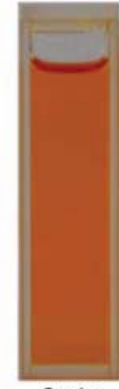

$3 \min$

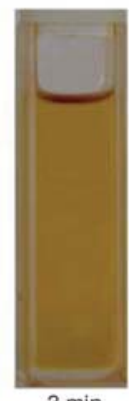

tion of pMACP and pMAMP in $\mathrm{CHCl}_{3}$ solutions were studied. The polymer solutions were irradiated with $365 \mathrm{~nm}$ of UV light [43]. The UV-vis spectra of the samples after irradiated under $365 \mathrm{~nm}$ of UV light for different time were recorded as shown in Figure 7. The electronical properties of substituted group on azobenzene ring showed obvious effect on the photo isomerization behavior of polymer. It was interesting to find that the pMACP with electron donor (substituted amino group) and acceptor (cyano group) structure inside showed the enhanced absorption at 511 and $550 \mathrm{~nm}$ corresponding to $n-\pi^{*}$ transition in cis isomer. At the same time, the absorption band corresponding to $\pi-\pi^{*}$ transition in trans isomer at around $445 \mathrm{~nm}$ decreased remarkable (Figure 7a). During the transcis isomerization, the absorption peak at 521 and $445 \mathrm{~nm}$ showed serious overlap each other, which results in the appearance of a 'red-shift' peak from 445 to $528 \mathrm{~nm}$. In the case of pMAMP with only the electron donor groups (substituted amino group and methoxy group), the similar results as pMACP under the irradiation of $365 \mathrm{~nm}$ light were observed, e.g. the enhancement of cis isomer $n-\pi^{*}$ transition peak at $545 \mathrm{~nm}$ and weaken of trans isomer $\pi-\pi^{*}$ transition peak at $412 \mathrm{~nm}$. The red shift of $\pi-\pi^{*}$ transition in electron-donor/acceptor substituted azobenzene, e.g. pMACP at $445 \mathrm{~nm}$, compared with that of the electron-donating groups

Figure 8. Color changes of pMACP and pMAMP in $\mathrm{CHCl}_{3}$ solution with different irradiation time under $365 \mathrm{~nm}$ of UV light at room temperature. The concentration of the solution was $2.5 \cdot 10^{-6} \mathrm{~mol} \cdot \mathrm{L}^{-1}$. (a) for pMACP and (b) for pMAMP. The pMACP and pMAMP polymers used are the same as present in Figure 5. 
substituted azobenzene, e.g. pMAPM at $412 \mathrm{~nm}$, was observed [44]. While the $n-\pi^{*}$ transition is nearly constant in these cases, e.g. ranged from 520 to $550 \mathrm{~nm}$ [44]. It should be further noted that the red-shift value of pMAMP was much higher than that of pMACP, e.g. about $136 \mathrm{~nm}$ for pMAMP and $110 \mathrm{~nm}$ for pMACP, as showed in UV-vis spectra among the trans-cis transformation. Thus the color change of pMAMP solution under UV light of $365 \mathrm{~nm}$ irradiation should be more obvious than that of pMACP.

As shown in Figure 8, the color of pMAMP solution changed gradually from light yellow to purple with the irradiation time under $365 \mathrm{~nm}$ of UV light. However, it gradually changed from yellow to red for the color of pMACP solution under the irradiation of $365 \mathrm{~nm}$ of UV light. After 20 min of irradiation, further prolongation of the irradiation time did not show any color changes in both cases, which indicated that the trans-cis isomerization of azobenzene chromophores reached saturation after $20 \mathrm{~min}$ of irradiation.

The trans-cis isomerization showed thermally reversible properties in these two polymers solutions. The UV-vis spectra of the samples in chloroform during the thermal cis-trans isomerization process at $50^{\circ} \mathrm{C}$ for different time were traced and recorded as shown in Figure 9. The cis-trans isomerization completed after $12 \mathrm{~h}$ for pMACP, while it was $60 \mathrm{~h}$ for pMAMP. This result indicated that the electron donor-acceptor substitution on azobenzene ring would show significant effect on cis-trans isomerization rate [44]. Such isomerization rate of electron donor substituted azobenzene (pMAMP) was much slower than that of electron donor-acceptor substituted azobenzene (pMACP). To further testified such behavior, the photo isomerization kinetics were investigated using a similar method appeared in literature [43].

The trans-to-cis isomerization rates were recorded by determining the absorbance at $450 \mathrm{~nm}$ for pMACP and $415 \mathrm{~nm}$ for pMAMP, respectively, corresponding to the $\pi-\pi^{*}$ transition, after different irradiation time under $365 \mathrm{~nm}$ of UV light. The results are shown in Figure 10. The cis-to-trans isomerization rates were determined by tracking the $\mathrm{UV}$-vis spectra for the pre-tran-cis isomerization saturated polymer solutions irradiated with $470 \mathrm{~nm}$ of UV light. The spectra changes of the reverse cistrans photoisomerization at different time intervals
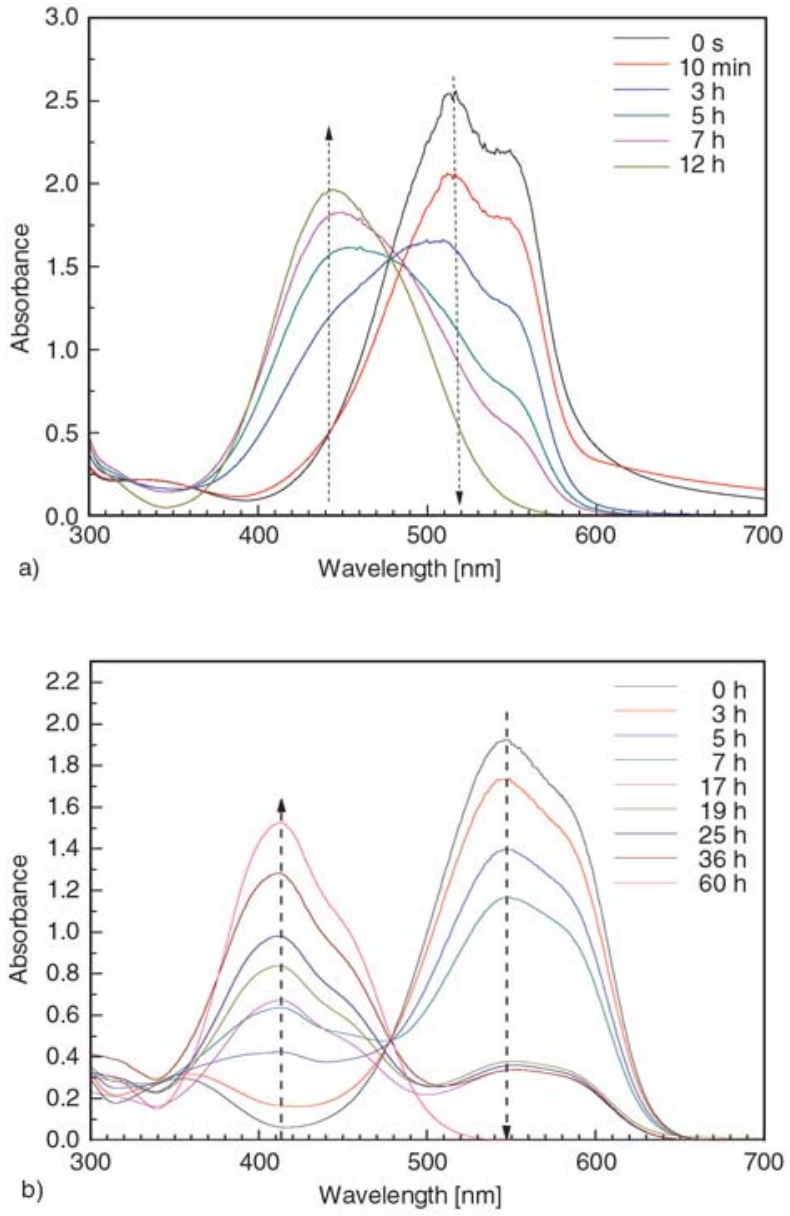

Figure 9. Changes in the UV-vis absorption spectra of $\operatorname{pMACP}\left(\mathrm{a}-M_{n(G P C)}=10550 \mathrm{~g} \cdot \mathrm{mol}^{-1}, \mathrm{PDI}=\right.$ $1.30)$ and $\mathrm{pMAMP}\left(\mathrm{b}-M_{n(G P C)}=8580 \mathrm{~g} \cdot \mathrm{mol}^{-1}\right.$, $\mathrm{PDI}=1.27$ ) in chloroform solution during the thermal cis-trans isomerization process at $50^{\circ} \mathrm{C}$. The concentration of the solution was $2.5 \cdot 10^{-6} \mathrm{~mol} \cdot \mathrm{L}^{-1}$.

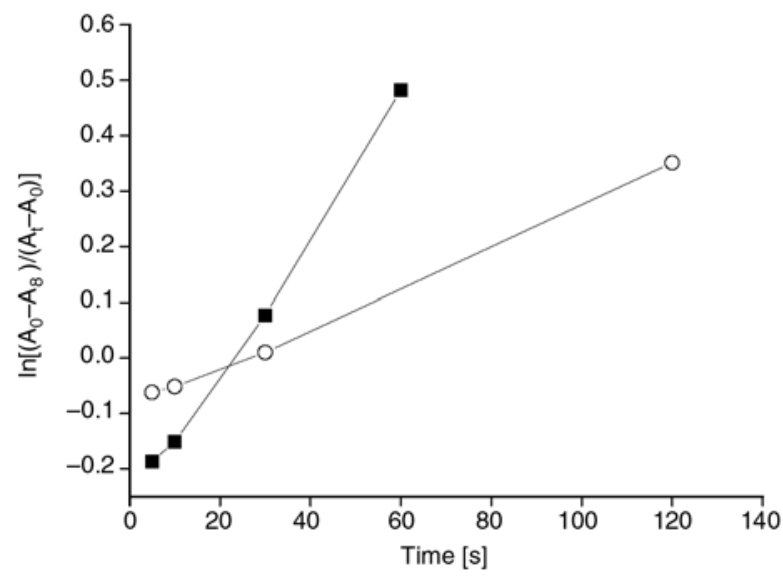

Figure 10. First-order plots for trans-cis isomerization of pMACP ( $\square)$ and pMAMP (o). The concentration of polymer solution was $2.5 \cdot 10^{-6} \mathrm{~mol} \cdot \mathrm{L}^{-1}$, and the data were respectively recorded by monitor the absorbance at 450 and $415 \mathrm{~nm}$ for pMACP and pMAMP with different time interval under $365 \mathrm{~nm}$ of UV light irradiation. 


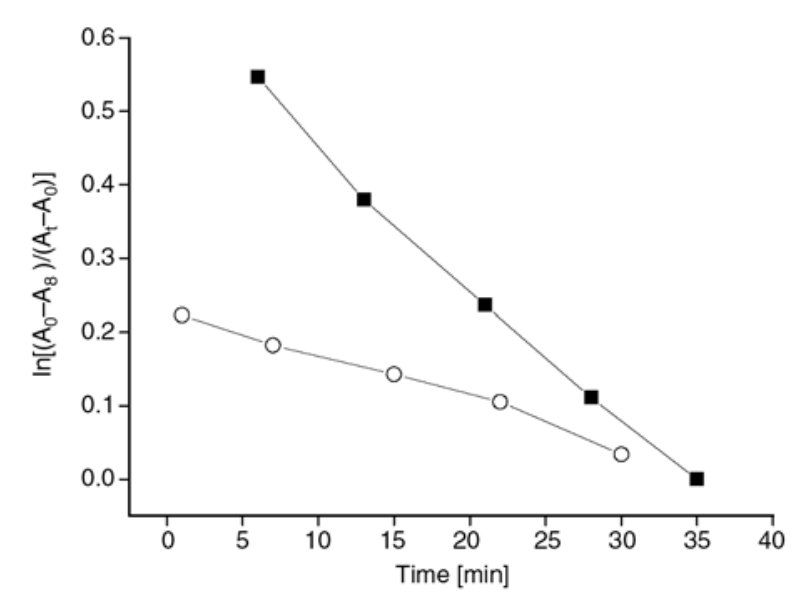

Figure 11. First-order plots for cis-trans isomerization of pMACP (匹) and pMAMP (o). The concentration of polymer solution was $2.5 \cdot 10^{-6} \mathrm{~mol} \cdot \mathrm{L}^{-1}$, and the data were respectively recorded by monitor the absorbance at 450 and $415 \mathrm{~nm}$ for pMACP and pMAMP with different time interval under $470 \mathrm{~nm}$ of UV light irradiation.

are shown in Figure 11. The first-order rate constants were determined by fitting the experimental data to the Equation (2) [45, 46]:

$\ln \left(\frac{A_{\infty}-A_{0}}{A_{\infty}-A_{t}}\right)=-k_{t c} t$

where $A_{t}, A_{0}$ and $A_{\infty}$ are absorbance at the maximum wavelength of $450 \mathrm{~nm}$ for pMACP and $415 \mathrm{~nm}$ for pMAMP at time $t$, time zero and infinite time (300 s in current experiment), respectively. The first-order plots according to this equation for trans-cis isomerization and cis-trans isomerization of azobenzene chromophore were shown in Figure 10 and Figure 11, respectively. The trans-cis photoisomerization rate constant, $k_{t c}$, as measured at room temperature in $\mathrm{CHCl}_{3}$ were $0.0123 \mathrm{~s}^{-1}$ for pMACP and $0.0036 \mathrm{~s}^{-1}$ for pMAMP, respectively. The cis-trans photoisomerization rate constant, $k_{t c}$, as measured at room temperature in $\mathrm{CHCl}_{3}$ were $0.0187 \mathrm{~min}^{-1}$ for pMACP and $0.0063 \mathrm{~min}^{-1}$ for pMAMP, respectively. The rates of trans-cis and cis-trans isomerization of pMAMP were slower than those of pMACP. The reason could be attributed to the donor-acceptor effect which effectively increased the energy of the $\mathrm{N}=\mathrm{N} \pi$-bonding orbital, thus lower the energy of the $\pi^{*}$-antibonding orbital, then lowering the overall energy of the $\pi-\pi^{*}$ transition [47].

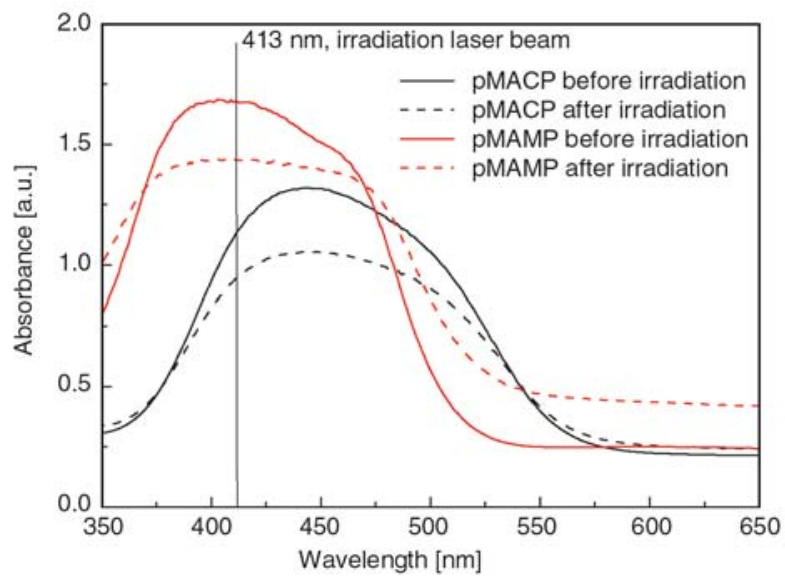

Figure 12. UV-vis absorption spectra of the films of $\operatorname{pMACP}\left(M_{n(G P C)}=8810 \mathrm{~g} \cdot \mathrm{mol}^{-1}, \mathrm{PDI}=1.28\right)$ and pMAMP $\left(M_{n(G P C)}=8820 \mathrm{~g} \cdot \mathrm{mol}^{-1}\right.$, PDI $=1.27$ ) on quartz glass before and after irradiation by $413 \mathrm{~nm}$ of UV light

\subsection{Photoinduced birefringence}

It is well-known that a good matching of the absorption wavelength with the wavelength of the pumping laser has a positive effect on storage efficiency [10]. Being the absorption spectra of the investigated polymers quite similar, a laser light operating at $413.1 \mathrm{~nm}$, in resonance with their intense electronic transition in the visible (Figure 12), has been used in the irradiation experiments in order to gain the same pumping efficiency. To assess the presence of photo-induced birefringence, films from pMACP $\left(M_{n(G P C)}=8810 \mathrm{~g} \cdot \mathrm{mol}^{-1}\right.$, $\mathrm{PDI}=1.28)$ and $\mathrm{pMAMP}\left(M_{n(G P C)}=8820 \mathrm{~g} \cdot \mathrm{mol}^{-1}\right.$, PDI $=1.27$ ) were prepared by spin coating method. The film thicknesses were $107 \mathrm{~nm}$ for pMACP and $120 \mathrm{~nm}$ for pMAMP. Polymers films were irradiated with linearly polarized radiation (writing step) at $413.1 \mathrm{~nm}$ of wavelength under $5 \mathrm{~mW} / \mathrm{cm}^{2}$ of light intensity $(I)$. After irradiation, the polymers showed high photo-induced linear birefringence (Figure 13) due to the homogeneously regular alignment of azobenzene chromophores, as evidenced by using a probe radiation at $650 \mathrm{~nm}$, where the samples exhibit negligible absorption. The birefringence values can be determined by fitting the experimental data to the Equation (3):

$$
\Delta n=\frac{\lambda}{\pi d} \arcsin \sqrt{\frac{I}{I_{0} \sin ^{2} 2 \theta}}=\frac{\lambda}{\pi d} \arcsin \sqrt{\frac{I}{I_{0}}}
$$




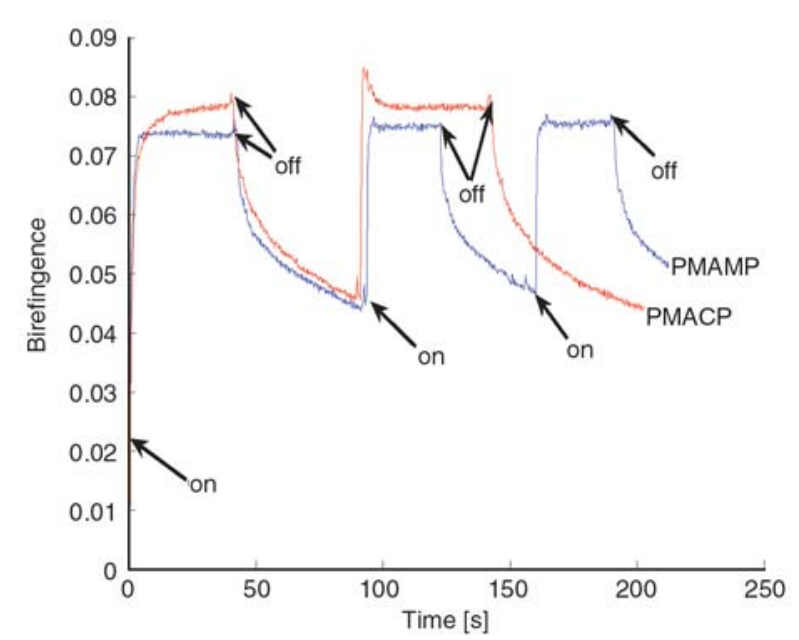

Figure 13. Photoinduced birefringence of pMACP $\left(M_{n(G P C)}=8810 \mathrm{~g} \cdot \mathrm{mol}^{-1}, \mathrm{PDI}=1.28\right)$ and $\operatorname{pMAMP}\left(M_{n(G P C)}=8820 \mathrm{~g} \cdot \mathrm{mol}^{-1}, \mathrm{PDI}=1.27\right)$ films

where $\theta=45^{\circ}, \Delta n$ is the birefringence, $\lambda$ is the wavelength of detection laser, $d$ is the thickness of sample, $I_{0}$ is the intensity of polarized incident laser and $I$ is the detected transition laser intensity after turn on the pump beam, $\theta$ is the angle of polarization between the pump beam and detect laser. Here, $\theta$ is $45^{\circ}$.

The birefringence was induced immediately under irradiation with a linearly polarized UV laser as the result of the alignment of the azo chromophores perpendicular to the laser polarization occurred on account of the trans-cis-trans isomerization of azo moieties. The rate of inducing birefringence of these polymer films was similar under the same writing beam power. Thus, these two substitution group $\left(-\mathrm{CN}\right.$ and $\left.-\mathrm{OCH}_{3}\right)$ bearing on the azobenzene chromophore did not show obvious effects on birefringence due to the similar size of these two groups [20]. The birefringence stabilized after turn on the inducing UV laser about $4 \mathrm{~s}$ for pMAMP and $6 \mathrm{~s}$ for pMACP. The maximum value of the photoinduced birefringence was about 0.073 for pMAMP and 0.079 for pMACP, respectively. After turn off the inducing UV laser, the birefringence was lost due to the azo chromophores relaxation. Finally, the birefringence of these two polymer films seems to be stabilized lower than 0.04. After that, the cycle between the birefringence induction and relaxation can be repeated in the same manner with the same level of birefringence at the same rate.

\subsection{Photoinduced surface relief grating}

For optical storage properties, creation of local holographic gratings is very important, and it is customary to report the diffraction efficiencies achieved on various materials [48]. SRG forming behavior of the synthesized azo polymers was characterized by the inscription rates and the saturation levels of SRG formation. The first order diffraction efficiency of the SRGs recorded in situ was used to characterize the surface modification [49-52]. The results were also compared with the surface deformation obtained from the AFM images. Low intensity of $\mathrm{Kr}^{+}$laser irradiation $\left(30 \mathrm{~mW} / \mathrm{cm}^{2}\right)$ was applied for the writing experiments in order to avoid the possible side effects caused by high intensity laser irradiation. For the comparable results, the laser intensity was kept the same during the experiments. The film thicknesses were $185 \mathrm{~nm}$ for pMACP and $200 \mathrm{~nm}$ for pMAMP.

It is worth to discuss the possible effects of polarity of the azobenzene groups on the SRG. Figure 14 shows the diffraction efficiency as a function of irradiation time for the films of $\mathrm{pMACP}\left(M_{n(G P C)}=\right.$ $\left.8810 \mathrm{~g} \cdot \mathrm{mol}^{-1}, \mathrm{PDI}=1.28\right)$ and $\mathrm{pMAMP}\left(M_{n(G P C)}=\right.$ $8820 \mathrm{~g} \cdot \mathrm{mol}^{-1}$, PDI $\left.=1.27\right)$. In both cases, the diffraction efficiency of the SRGs increased with irradiation time and no difference of diffraction efficiency between them was found.

The formation of the SRG was confirmed by AFM images. Figure 15. (a 1) and 15. (b 1) show atomic force microscopy (AFM) image of the sinusoidal surface relief structures with regular spaces formed

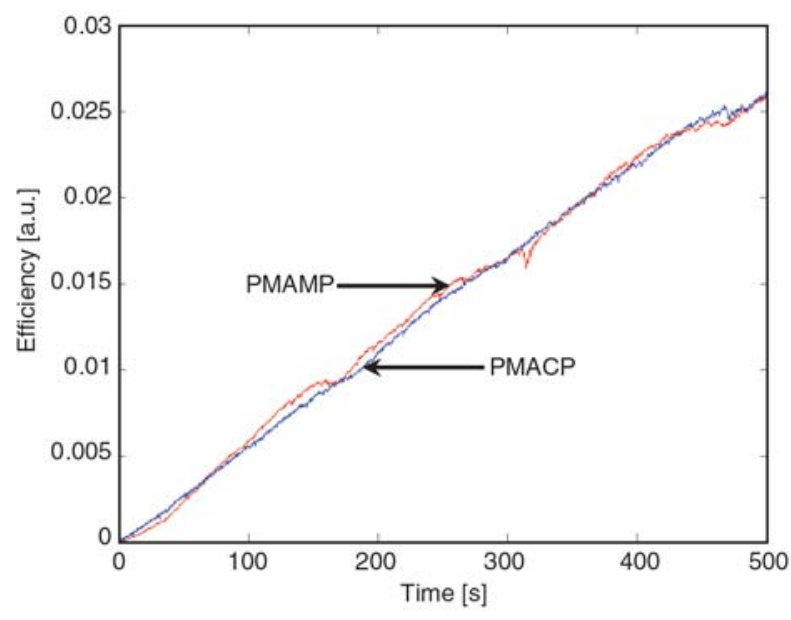

Figure 14. First-order diffraction efficiency signal for the gratings inscribed in pMACP $\left(M_{n(G P C)}=\right.$ $\left.8810 \mathrm{~g} \cdot \mathrm{mol}^{-1}, \mathrm{PDI}=1.28\right)$ and $\mathrm{pMAMP}$ $\left(M_{n(G P C)}=8820 \mathrm{~g} \cdot \mathrm{mol}^{-1}, \mathrm{PDI}=1.27\right)$ 

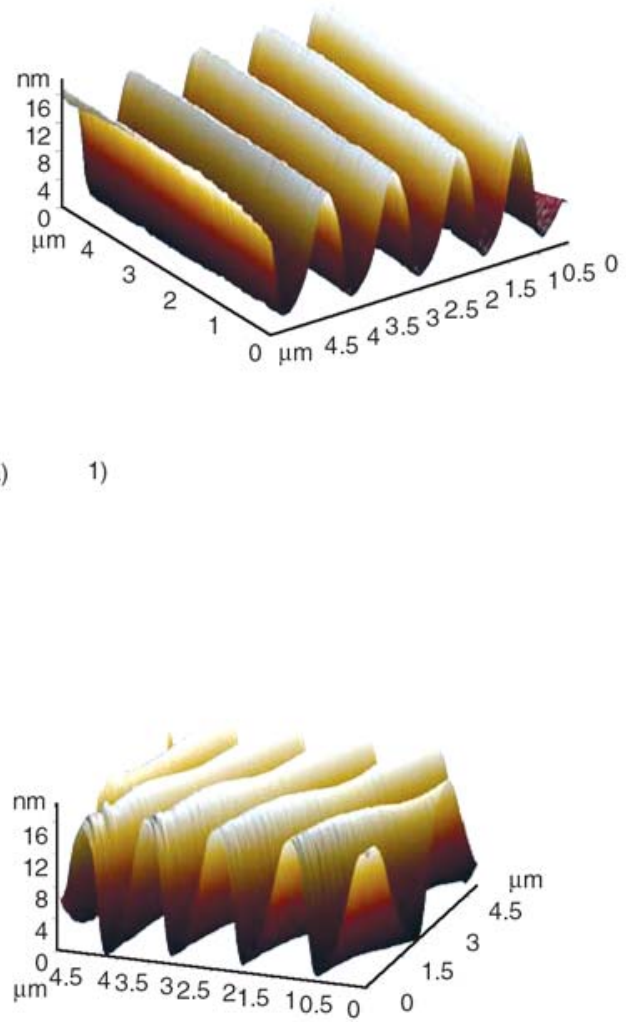

b) 1)

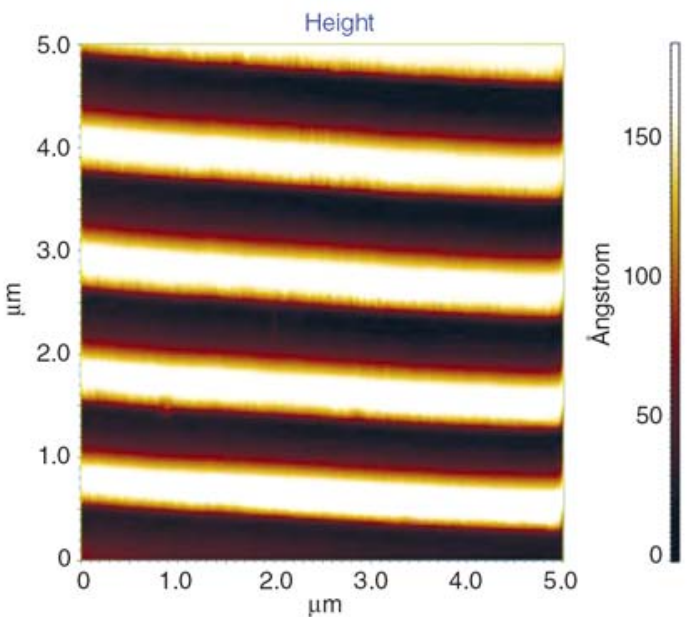

2)

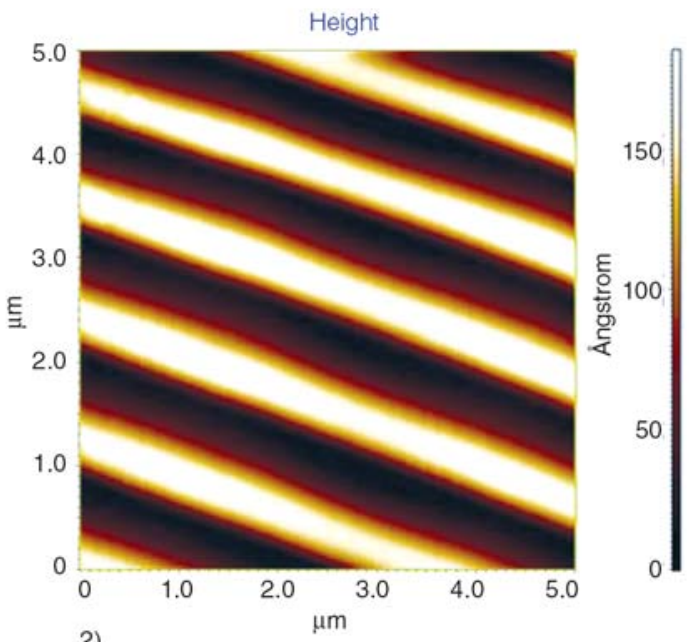

Figure 15. a - AFM images of the SRG inscribed on the pMACP film, prepared from sample with $M_{n(G P C)}=$ $8810 \mathrm{~g} \cdot \mathrm{mol}^{-1}$, PDI $=1.28 \mathrm{~b}-\mathrm{AFM}$ images of the SRG inscribed on the pMAMP film, prepared from sample with $M_{n(G P C)}=8820 \mathrm{~g} \cdot \mathrm{mol}^{-1}, \mathrm{PDI}=1.27$.

on the pMACP and pMAMP films. The grating depths, obtained through the AFM, were 15 and $18 \mathrm{~nm}$ for the samples (a) pMACP $\left(M_{n(G P C)}=\right.$ $8810 \mathrm{~g} \cdot \mathrm{mol}^{-1}$, PDI $=1.28$ ) and (b) $\mathrm{pMAMP}$ $\left(M_{n(G P C)}=8820 \mathrm{~g} \cdot \mathrm{mol}^{-1}, \mathrm{PDI}=1.27\right)$, respectively. Figure 15. (a 2) and 15. (b 2) show the AFM images of the SRG. The typical AFM images of the SRG with a grating periodicity around $1.0 \mu \mathrm{m}$ were observed in these two polymer films.

\section{Conclusions}

Two azo polymers, pMACP and pMAMP with electronical push and pull substituents were synthesized through RAFT polymerizations. The polymerization showed the characteristics of 'living'/ controlled free radical polymerization. The isomerization rate of pMAMP was much slower than that of pMACP due to the donor-acceptor effect of the substituted azobenzene. The solution color of the polymers could be changed under irradiation of $365 \mathrm{~nm}$ of UV light because of the $\pi-\pi^{*}$ transition in trans isomer to $n-\pi^{*}$ transition in cis isomer. The light induced tran-cis isomerizations were confirmed to be thermally reversible. For the pMACP and pMAMP films, the diffraction efficiency of the SRGs increased with irradiation time and regular SRG images were obtained.

\section{Acknowledgements}

The financial supports of this work by the National Nature Science Foundation of China (No. 20574050), the Science and Technology Development Planning of Jiangsu Province (No. BK2007702 and BK2007048), the International Cooperation Foundation of Jiangsu Province (No. BZ2007037) and the Nature Science Key Basic Research of Jiangsu Province for Higher Education (No. 05KJA15008) are gratefully acknowledged. 


\section{References}

[1] Gibbons W. M., Shannon P. J., Sun S-T., Swetlin B. J.: Surface-mediated alignment of nematic liquid crystals with polarized laser light. Nature, 351, 49-50 (1991).

[2] Holme N. C. R., Ramanujam P. S., Hvilsted S.: 10000 Optical write, read, and erase cycles in an azobenzene side-chain liquid-crystalline polyester. Optical Letters, 21, 902-904 (1996).

[3] Katz H., Singer K., Sohn J., Dirk C., King L. A., Gordon H. M.: Greatly enhanced second-order nonlinear optical susceptibilities in donor-acceptor organic molecules. Journal of American Chemical Society, 109, 6561-6563 (1987).

[4] Delaire J. A., Nakatani K.: Linear and nonlinear optical properties of photochromic molecules and materials. Chemical Reviews, 100, 1817-1846 (2000).

[5] Todorov T., Nikolova L., Tomova N.: Polarization holography. 2: Polarization holographic gratings in photoanisotropic materials with and without intrinsic birefringence. Applied Optics, 23, 4588-4591 (1984).

[6] Andruzzi L., Altomare A., Ciardelli F., Solaro R., Hvilsted S., Ramanujam P. S.: Holographic gratings in azobenzene side-chain polymethacrylates. Macromolecules, 32, 448-454 (1999).

[7] Iftime G., Abarthet F. L., Natansohn A., Rochon P.: Control of chirality of an azobenzene liquid crystalline polymer with circularly polarized light. Journal of American Chemical Society, 122, 12646-12650 (2000).

[8] Verbiest T., Kauranen M., Persoons A.: Second-order nonlinear optical properties of chiral thin films. Journal of Materials Chemistry, 9, 2005-2012 (1999).

[9] Wu Y., Natasohn A., Rochon P.: Photoinduced birefringence and surface relief gratings in polyurethane elastomers with azobenzene chromophore in the hard segment. Macromolecules, 37, 6090-6095 (2004).

[10] Natansohn A., Rochon P.: Photoinduced motions in azo-containing polymers. Chemical Reviews, 102, 4139-4176 (2002).

[11] Mita I., Horie K., Hirao K.: Photochemistry in polymer solids. 9. Photoisomerization of azobenzene in a polycarbonate film. Macromolecules, 22, 558-563 (1989).

[12] Naito T., Horie K., Mita I.: The effect of polymer rigidity on photoisomerization of 4-dimethylamino-4'nitroazobenzene. Polymer Journal, 23, 809-813 (1991).

[13] Ivanov S., Yakovlev I., Kostromin S., Shibaev V., Läsker L., Stumpe J., Kreysig D.: Laser-induced birefringence in homeotropic films of photochromic comb-shaped liquid-crystalline copolymers with azobenzene moieties at different temperatures. Die Makromolekulare Chemie, Rapid Communications, 12, 709-715 (1991).
[14] Wiesner U., Reynolds N., Boeffel C., Spiess H. N.: Photoinduced reorientation in liquid-crystalline polymers below the glass transition temperature studied by time-dependent infrared spectroscopy. Die Makromolekulare Chemie, Rapid Communications, 12, 457 464 (1991).

[15] Meerholz K., Volodin B. L., Sandalphon B., Kippelen B., Peyghambarian N.: A photorefractive polymer with high optical gain and diffraction efficiency near 100\%. Nature, 371, 497-500 (1994).

[16] Rochon P., Batalla E., Natansohn A.: Optically induced surface gratings on azoaromatic polymer films. Applied Physics Letters, 66, 136-138 (1995).

[17] Sekkat Z., Wood J., Knoll W.: Reorientation mechanism of azobenzenes within the trans .fwdarw. cis photoisomerization. Journal of Physical Chemistry, 99, 17226-17234 (1995).

[18] Ding L., Russell T. P.: A photoactive polymer with azobenzene chromophore in the side chains. Macromolecules, 40, 2267-2270 (2007).

[19] Lissi E. A., Encinas M. V.: Photoinitiators for free radical polymerization. in 'Photochemistry and Photophysics' (ed.: Rabek J. F.) CRC Press, Boca Raton, vol 4, 221-294 (1990).

[20] Ho M. S., Barrett C., Natansohn A., Rochon P.: Azo polymers for reversible optical storage. 8 . The effect of polarity of the azobenzene groups. Canadian Journal of Chemistry, 73, 1773-1778 (1995).

[21] Cui L., Tong X., Yan X., Liu G., Zhao Y.: Photoactive thermoplastic elastomers of azobenzene-containing triblock copolymers prepared through atom transfer radical polymerization photoactive thermoplastic elastomers of azobenzene-containing triblock copolymers prepared through atom transfer radical polymerization. Macromolecules, 37, 7097-7104 (2004).

[22] Mandal B. K., Jeng R. J., Kumar J., Tripathy S. K.: New photocrosslinkable polymers for second-order nonlinear optical processes. Die Makromolekulare Chemie, Rapid Communications, 12, 607-612 (1991).

[23] Lambeth R. H., Moore J. S.: Light-induced shape changes in azobenzene functionalized polymers prepared by ring-opening metathesis polymerization. Macromolecules, 40, 1838-1842 (2007).

[24] Wang X., Chen J-I., Marturunkakul S., Li L., Kumar J., Tripathy S. K.: Epoxy-based nonlinear optical polymers functionalized with tricyanovinyl chromophores. Chemistry of Materials, 9, 45-50 (1997).

[25] Wang X., Kumar J., Tripathy S. K., Li L., Chen J-I., Marturunkakul S.: Epoxy-based nonlinear optical polymers from post azo coupling reaction. Macromolecules, 30, 219-225 (1997).

[26] He Y., Yin J., Che P., Wang X.: Epoxy-based polymers containing methyl-substituted azobenzene chromophores and photoinduced surface relief gratings. European Polymer Journal, 42, 292-301 (2006).

[27] Li Y., Deng Y., He Y., Tong X., Wang X.: Amphiphilic azo polymer spheres, colloidal monolayers, and photoinduced chromophore orientation. Langmuir, 21, 6567-6571 (2005). 
[28] Kato M., Kamigaito M., Sawamoto M., Higashimura T.: Polymerization of methyl methacrylate with the carbon tetrachloride/dichlorotris- (triphenylphosphine)ruthenium(II)/methylaluminum bis(2,6-di-tertbutylphenoxide) initiating system: Possibility of living radical polymerization. Macromolecules, 28, 17211723 (1995).

[29] Wang J-S., Matyjaszewski K.: Controlled/‘living’ radical polymerization. Halogen atom transfer radical polymerization promoted by a $\mathrm{Cu}(\mathrm{I}) / \mathrm{Cu}(\mathrm{II})$ redox process. Macromolecules, 28, 7901-7910 (1995).

[30] Matyjaszewski K., Xia J. H.: Atom transfer radical polymerization. Chemical Reviews, 101, 2921-2990 (2001).

[31] Chiefari J., Chong Y. K., Ercole F., Kristina J., Jeffery J., Le T. P. T., Mayadunne R. T. A., Meijs G. F., Moad C. L., Moad G., Rizzardo E., Thang S. H.: Living freeradical polymerization by reversible addition-fragmentation chain transfer: The RAFT process. Macromolecules, 31, 5559-5562 (1998).

[32] Moad G., Rizzardo E., Thang S. H.: Living radical polymerisation by the RAFT process. Australian Journal of Chemistry, 58, 379-410 (2005).

[33] Moad G., Rizzardo E., Thang S. H.: Living radical polymerization by the RAFT process: A first update. Australian Journal of Chemistry, 59, 669-692 (2006).

[34] Moad G., Rizzardo E., Thang S. H.: Radical additionfragmentation chemistry in polymer synthesis. Polymer, 49, 1079-1131 (2008).

[35] Barner-Kowollik C.: Handbook of RAFT polymerization. Wiley-VCH, Weinheim (2008).

[36] Favier A., Charreyre M-T.: Experimental requirements for an efficient control of free-radical polymerizations via the reversible addition-fragmentation chain transfer (RAFT) process. Macromolecular Rapid Communications, 27, 653-692 (2006).

[37] Zhang Y., Cheng Z., Chen X., Zhang W., Wu J., Zhu J., Zhu X. L.: Synthesis and photoresponsive behaviors of well-defined azobenzene-containing polymers via RAFT polymerization. Macromolecules, 40, 4809-4817 (2007).

[38] Sun B., Zhu X., Zhu J., Cheng Z., Zhang Z.: A novel synthetic method for well-defined polymer containing benzotriazole and bisazobenzene chromophore. Macromolecular Chemistry and Physics, 208, 1101-1109 (2007).

[39] Hawker C. J., Bosman A. W., Harth E.: New polymer synthesis by nitroxide mediated living radical polymerizations. Chemical Reviews, 101, 3661-3688 (2001).

[40] Chong Y. K., Krstina J., Le T. P. T., Moad G., Postma A., Rizzardo E., Thang S. H.: Thiocarbonylthio compounds $[\mathrm{S}=\mathrm{C}(\mathrm{Ph}) \mathrm{S}-\mathrm{R}]$ in free radical polymerization with reversible addition-fragmentation chain transfer (RAFT Polymerization). Role of the free-radical leaving group (R). Macromolecules, 36, 2256-2272 (2003).
[41] Kim D. Y., Li L., Kumar J., Tripathy S. K.: Laserinduced holographic surface relief gratings on nonlinear optical polymer films. Applied Physics Letters, 66, 1166-1168 (1995).

[42] Barner-Kowollik C., Buback M., Charleux B., Coote M. L., Darche M., Fukuda T., Goto A., Klumperman B., Klumperman B., Lowe A. B., Mcleary J. B., Moad G., Monteiro M. J., Sanderson R. D., Tonge M. P., Vana P.: Mechanism and kinetics of dithiobenzoatemediated RAFT polymerization. I. The current situation. Journal of Polymer Science, Part A: Polymer Chemistry, 44, 5809-5831 (2006).

[43] Zhang Q-Z., Sheng X., Li A-X., Yan W.: Study on photochemistry of photochromic liquid crystalline dendrimer of the first generation containing nitro groups (in Chinese). Acta Chimical Sinica, 14, 1335 1342 (2005).

[44] Rau H.: Photoisomerization of azobenzenes. in 'Photoreactive Organic Thin Films'. (eds.: Sekkat Z., Knoll W. ) Elsevier Science, San Diego, 3-49 (2002).

[45] Sin S. L., Gan L. H., Hu X., Tam K. C., Gan Y. Y.: Photochemical and thermal isomerizations of azobenzene-containing amphiphilic diblock copolymers in aqueous micellar aggregates and in film. Macromolecules, 38, 3943-3948 (2005).

[46] Sasaki T., Ikeda T., Ichimura K.: Photoisomerization and thermal isomerization behavior of azobenzene derivatives in liquid-crystalline polymer matrixes. Macromolecules, 26, 151-154 (1993).

[47] Rau H.: Photoisomerization of azobenzenes. in 'Photochemistry and Photophysics' (ed.: Rabek J. F.) CRC Press, Boca Raton, vol 2, 119-141 (1990).

[48] Natansohn A., Rochon P., Ho M-S., Barrett C.: Azo polymers for reversible optical storage. VI. poly[4-[2(methacryloyloxy)ethyl]azobenzene. Macromolecules, 28, 4179-4183 (1995).

[49] Barrett C., Natansohn A. L., Rochon P. L.: Mechanism of optically inscribed high-efficiency diffraction gratings in azo polymer films. Journal of Physical Chemistry, 100, 8836-8842 (1996).

[50] Ho M. S., Barrett C., Paterson J., Esteghamatian M., Natansohn A., Rochon P.: Synthesis and optical properties of poly\{(4-nitrophenyl)-[3-[N-[2-(methacryloyloxy)ethyl]-carbazolyl]]diazene $\}$. Macromolecules, 29, 4613-4618 (1996).

[51] Jiang X. L., Li L., Kumar J., Kim D. Y., Tripathy S. K.: Unusual polarization dependent optical erasure of surface relief gratings an azobenzene polymer film. Applied Physics Letters, 72, 2502-2504 (1998).

[52] Tripathy S., Kim D. Y., Li L., Kumar J.: Photofabrication of surfaces for holograms. Chemtech, 28, 34-40 (1998). 